\title{
Workload für Teilnehmer
}

Im aufgeführten Workload in Abb. 3.1 bezieht sich je ein Aufgabenblock auf Erfahrungswerte im Rahmen der Einzelbearbeitung der Fallstudie und kann daher nur ein Richtwert sein.

\begin{tabular}{|c|l|r|}
\hline $\begin{array}{c}\text { Aufgaben- } \\
\text { block }\end{array}$ & Thema des Aufgabenblocks & $\begin{array}{c}\text { Bearbeitungs- } \\
\text { dauer (ø) }\end{array}$ \\
\hline 0 & $\begin{array}{l}\text { Einarbeitung (Sichten bzw. Lesen der verfügbaren Dokumente ggf. erste } \\
\text { Recherchetätigkeiten) }\end{array}$ & $4-5$ Std. \\
\hline 1 & Standortbewertung & $10-12$ Std. \\
\hline 2 & Selbstkosten und Kapitalstrukturen & $9-11$ Std. \\
\hline 3 & Wirtschaftlichkeitsberechnungen I & $12-14$ Std. \\
\hline 5 & Potenzialanalyse & $9-10$ Std. \\
\hline 6 & Wirtschaftlichkeitsberechnungen II & $8-10$ Std. \\
\hline 7 & Abschließende betriebswirtschaftliche Bewertung & $6-8$ Std. \\
\hline 8 & Einfluss auf die Region (CSR) & $10-11$ Std. \\
\hline 9 & Transfer zwischen Fallstudie und eigener beruflicher Erfahrung & $3-4$ Std. \\
\hline Abschluss & Präsentation der Ergebnisse mit anschließender Diskussion * & $15-18$ Std. \\
\hline & * Dauer je nach Teilnehmerzahl oder Gruppengrößen & $2-4$ Std. \\
\hline
\end{tabular}

Abb. 3.1 Workload für Teilnehmer 